Revista Verde de Agroecologia e Desenvolvimento Sustentável

http://www.gvaa.com.br/revista/index.php/RVADS

ARTIGO CIENTÍFICO

[SSW ๆ९OA+8208

DOI: http://dx.doi.org/10.18378/rvads.v10i3.3909

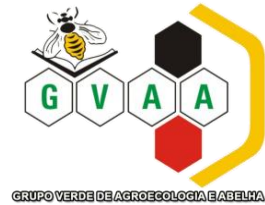

\title{
Obtenção de corante do repolho roxo (Brassica oleracea) por dois métodos de extração
}

\section{Red cabbage dye obtaining (Brassica oleracea) by two extraction methods}

\author{
Janailson da Costa Almeida ${ }^{1}$, Danielle de Sousa Severo ${ }^{2}$, Alfredina dos Santos Araújo ${ }^{3}$, Maria Auxiliadora de Souto \\ Cordeiro ${ }^{4}$, José Nildo Vieira Deodato 5
}

\begin{abstract}
Resumo: O repolho é uma hortaliça folhosa, com grande versatilidade, não somente pelo seu valor nutritivo. Além de colorir a mistura, destaca-se pelo elevado teor de antocianinas e compostos fenólicos, contribuindo para a prevenção de doenças cardiovasculares, bem como de alguns tipos de câncer. As antocianinas são largamente encontradas na natureza e responsáveis pela maioria das colorações azuis, violeta e vermelhas de flores e frutos, sendo sua principal utilização como corante natural na indústria. O presente trabalho tem como objetivo a obtenção de um corante, antocianina, de repolho roxo (Brassica oleracea) por dois métodos distintos de extração. No corrente estudo, o extrato foi obtido por meio de procedimento alcoólico e aquoso. As características avaliadas foram: $\mathrm{pH}$; acidez total titulável; Teor de sólidos solúveis ( ${ }^{\circ}$ Brix); umidade; cinzas; proteínas; extração e quantificação de antocianinas totais; Vitamina C. O resultado encontrado para antocianina no repolho roxo in natura foi de $6,58 \mathrm{mg} / 100 \mathrm{~g}$, para o extrato por método alcoólico foi de 4,58 mg/100g e 5,33 mg/100g para o extrato aquoso. Observou-se que a extração pelo método aquoso teve um rendimento melhor, correspondente a $50 \%$ do seu valor inicial, a extração alcoólica foi de $30 \%$ do seu volume inicial.
\end{abstract}

Palavras-chaves: Antocianina, pigmentos, hortaliça, extração.

\begin{abstract}
Cabbage is avegetable crop with great versatility, not limited to its nutritional value. Besides coloring the mixture, it stands out for its high quantity of anthocyanin and phenolic compounds, which contribute to prevention of cardiovascular diseases and some types of cancer. Anthocyanins are widely found in nature and are responsible for the majority of blue, violet and red present in flowers and fruits. Thus, its main utilization is in industries as a natural dye. This study aims to obtain a colorant, anthocyanin, the red cabbage (Brassica oleracea) by two different extraction methods. In the present study, the cabbage extract was obtained through alcoholic and aqueous procedure. The pigment characteristics evaluated were: $\mathrm{pH}$, total titratable acidity, soluble solid content $\left({ }^{\circ}\right.$ Brix $)$, humidity, ashes, proteins, extraction and quantification of total anthocyanins, vitamin $\mathrm{C}$. The result found for anthocyanin in red cabbage in natura was $6.58 \mathrm{mg} / 100 \mathrm{~g}$. The results found for the extraction through alcoholic method and through aqueous method were $4.58 \mathrm{mg} / 100 \mathrm{~g}$ and $5.33 \mathrm{mg} / 100 \mathrm{~g}$, respectively. It was observed that the extraction through aqueous procedure had a better efficiency, corresponding to $50 \%$ of the initial volume, while alcoholic procedure was $30 \%$ of the initial volume.
\end{abstract}

Key words: anthocyanin, dye, vegetable, extraction.

\footnotetext{
*Autor para correspondência

Recebido para publicação em 10/05/2015; aprovado em 02/07/2015

${ }^{1}$ Graduado, UFCG, Pombal; (83) 99865-2925, janailson_sb_@hotmailcom.

${ }^{2}$ Graduanda, UFCG, danni_severo@hotmail.com

${ }^{3}$ Doutora, UFCG, alfredina@ @cta.ufcg.edu.br

${ }^{4}$ Mestrando do PPGSA, UFCG, Pombal

${ }^{5}$ Mestre do PPGSA, UFCG, Pombal
} 


\section{INTRODUÇÃO}

O repolho (Brassica oleraceae var. capitata) é uma planta herbácea, folhosa, com grande versatilidade, não somente pelo seu valor nutritivo, sobretudo cálcio proteína e vitamina $\mathrm{C}$, constituindo-se em alimento de excelente qualidade para grande parte da população (LÉDO et al.,2000), pelo seu caráter social por ser uma cultura em que se utiliza muita mão-de-obra, sendo cultivada essencialmente por pequenos agricultores (FILGUEIRA, 2000).

Existem duas espécies de repolho, o repolho liso $(B$. oleracea L. var. capitata L.), de maior expressão comercial no Brasil, e o repolho crespo (B. oleracea L var. sabauda Martens). São classificados segundo a forma (achatada e pontuda) e a cor da cabeça (verde ou branca e roxa) (TIVELLI e PURQUERIO, 2005).

O repolho roxo (Brassica oleracea) é uma hortaliça de cabeça, formada por folhas espessas, cerosas, conchoidais e imbricadas numa sobreposição de folhas. Destaca-se como fonte de vitamina $\mathrm{C}$, mas também fornece vitaminas B1, B2, E e K, além de sais minerais, sobretudo cálcio e fósforo. As variedades mais apropriadas ao processamento mínimo são as que têm alta compacidade da cabeça (cabeças mais firmes), por oferecer maior resistência ao corte e, consequentemente, resultar num produto de melhor qualidade. Estudos demonstram que o repolho é uma das principais hortaliças escolhidas quando se deseja a agregação de valor, sendo assim até mais valorizado que na sua forma in natura (SILVA, 2007).

O repolho é uma hortaliça folhosa, com grande versatilidade, não somente pelo seu valor nutritivo. É um produto rico de corante natural e tem caráter social, pois utiliza muita mão-de-obra, sendo cultivada essencialmente por pequenos agricultores (FILGUEIRA, 2008).

Os corantes naturais são usados como forma de manter a coloração dos alimentos. Frequentemente os corantes dos alimentos sofrem séria degradação durante o processamento, e a restituição da cor perdida é uma maneira de manter o aspecto de frescor dos alimentos. Conhecer, quantificar e monitorar o processo de extração das antocianinas permitirá novos avanços para a obtenção de um processo rentável e viável (XAVIER, 2004).

$\mathrm{O}$ interesse nas antocianinas tem aumentado significativamente devido a suas cores atrativas, solubilidade em água (o que facilita sua incorporação em sistemas aquosos) e efeitos benéficos à saúde promovidos por estas através de diversos mecanismos de ação, incluindo a capacidade antioxidante. Seu potencial antioxidante é regulado por suas diferenças na estrutura química. Variando a posição e os tipos de grupos químicos nos anéis aromáticos das antocianinas, a capacidade de aceitar elétrons desemparelhados de moléculas de radicais também varia. Seu potencial antioxidante também é dependente do número e da posição dos grupos hidroxilas e sua conjugação, assim como da presença de elétrons doadores no anel da estrutura, devido à capacidade que o grupo aromático possui de suportar o desaparecimento de elétrons. Esta classe de compostos demonstrou também atividades anti-inflamatória, antiaterosclerótica e propriedades anticâncer em diversos estudos (COSTA, 2005; VOLP et al., 2009; TAFFARELLO, 2008).
As antocianinas são largamente encontradas na natureza e responsáveis pela maioria das colorações azul, violeta e vermelho das flores e frutos, sendo sua principal utilização na indústria, como corante natural (MALACRIDA; MOTTA, 2005). Elas apresentam propriedades que ajudam a manter hábitos saudáveis de alimentação que são demonstradas pelas as atividades anticarcinogênicas, antivirais e antioxidantes (WANG et al., 2000).

A população vem reavaliando sua dieta, consciente dos benefícios que o consumo de determinadas substância podem trazer à saúde. Com essa analogia diversos estudos científicos indicam efeitos positivos na ingestão de certos alimentos possuidores de corantes naturais a exemplo tem-se o repolho roxo, hortaliça elegida como protagonista desse estudo (DOS SANTOS, 2013).

A utilização de corantes na indústria de alimentos é de grande importância para as características sensórias do alimento, pois a cor e aparência têm papel fundamental na aceitação do produto pelos consumidores. E quando o assunto trata-se como corante natural, essa aceitação é ainda mais favorável devido tratar-se de um aditivo saudável (LOPES et al., 2000)

Com isso, o presente trabalho tem como objetivo a obtenção de um corante, antocianina, de repolho roxo (Brassica oleracea) por dois métodos distintos de extração.

\section{MATERIAL E MÉTODOS}

As amostras do repolho roxo foram adquiridas no mercado local da cidade de Pombal - PB e embaladas individualmente em sacos plásticos, transportadas em condições ambientes para Centro Vocacional Tecnológico (CVT) da Universidade Federal de Campina Grande (UFCG). As hortaliças foram lavadas em água corrente, em seguida, parte delas foram sanitizadas sendo imersas por aproximadamente 15 minutos em água contendo $25 \mathrm{ml} / \mathrm{L}$ (uma colher de sopa) de água sanitária, com posterior imersão em água destilada.

As analise físico-química realizada no repolho roxo e no extrato foram caracterizados pelos seguintes parâmetros: $\mathrm{pH}$, determinou-se pelo método potenciométrico, que baseiase na concentração hidrogeniônica usando o pHmetro. Seguindo método 017/IV determinado por IAL (2008). Sólidos solúveis totais, os resultados foram expressos em graus Brix $\left({ }^{\circ} \mathrm{B}\right),(\mathrm{IAL}, 2008)$. Acidez, os resultados foram expressos em porcentagem (\%) de ácido por 100 gramas do fruto, seguindo o método 016/IV do Instituto Adolf Lutz (2008).Teor de umidade, determinados através do método de secagem a $105^{\circ} \mathrm{C}$, em estufa ate que amostra permaneça em peso constante, de acordo com a metodologia 012/IV do Instituto Adolf Lutz (2008). Teor de Cinzas, Foi obtido pelo método gravimétrico que consiste na incineração do material em mufla a $550{ }^{\circ} \mathrm{C}$, determinadas segundo o método 018/IV do Instituto Adolf Lutz (2008).Teor de proteína, determinados através do método Kjedahl, 036/IV descrito pelo Instituto Adolfo Lutz (2008).Determinação de Ácido Ascórbico (Vitamina C) e teor de Antocianina, todas as analises foram realizadas em triplicatas.

$\mathrm{Na}$ determinação de antocianinas totais foi realizada segundo o método descrito por Lees e Francis (1972), com algumas adaptações. Para esta quantificação, em béqueres envoltos em papel alumínio, as amostras (repolho roxo in 
natura, Extrato Alcoólico e extrato aquoso do repolho roxo) foram homogeneizadas com solução extratora a base de etanol acidificado com ácido clorídrico e descansaram por 24 horas a temperatura de refrigeração. Após esse período as amostras foram filtradas com auxílio de papel de filtro e os resíduos lavados exaustivamente com a solução extratora até a remoção completa dos pigmentos. A absorbância foi medida a $535 \mathrm{~nm}$, em espectrofotômetro (modelo Spectrophotometer, SP 2000 UV).

Para a extração aquosa a espécie utilizada para obtenção dos extratos de repolho roxo foi a Brassica oleracea, onde foram utilizados aproximadamente $50 \mathrm{~g}$ de repolho roxo in natura, previamente triturado. Posteriormente, adicionou 150 $\mathrm{mL}$ de água destilada, aqueceu a solução a fervura até que a água reduza em $50 \%$ do volume inicial. O tempo da extração foi de aproximadamente 45 minutos, esperou-se a solução esfriar, para só então ser filtrada, sendo posteriormente armazenada em frasco escuro, em congelador doméstico (SOARES et al., 2001).

Na obtenção do extrato alcoólico foi utilizados $50 \mathrm{~g}$ de repolho roxo in natura, previamente triturado e empregando como solvente $100 \mathrm{~mL}$ de etanol 99,5\%; o tempo estabelecido para a extração foi de 48 horas. O béquer foi envolto por papel alumínio e mantido em temperatura ambiente, após este período filtrou-se a solução e levou o filtrado à evaporação em rota evaporador à temperatura de $49^{\circ} \mathrm{C}$, até obtenção de volume constante, o extrato foi armazenado em frasco escuro, em congelador doméstico (RAMOS et al.,2000)

\section{RESULTADOS E DISCUSSÃO}

Os resultados obtidos da caracterização físico-química do repolho roxo in natura e de seus extratos encontram-se expostos na Tabela 1.

Segundo os resultados apresentados na Tabela 1 , foi possível observar que os resultados de umidade dos extratos estão em quantidades maiores comparando ao do repolho in natura. Nos demais parâmetros o repolho in natura obteve resultados superiores.

$\mathrm{O}$ pH é um dos principais fatores limitante no processamento e utilização das antocianinas, comprometendo a estabilidade química e cor do pigmento. Em soluções ácidas, a antocianina é vermelha, mas com o aumento do $\mathrm{pH}$ a intensidade de cor diminui (MAZZA; BROUILLARD, 1987). Pesquisa realizada por Santos et al (2013) encontrando valor semelhantes de 5,91 para repolho roxo in natura e para o extrato valore de 4,32.

Segundo GOMES et al. (2002) enfatiza que os açúcares solúveis presentes nos frutos na forma combinada são responsáveis pela doçura, sabor e cor atrativas com o derivado das antocianinas. Os valores obtidos nessa pesquisa foram inferiores aos expostos por Santos et al(2013) que obteve 8,4 para o resultado no repolho in natura e 8,1 para o extrato. Santos et al. (2004) observam que o teor de sólidos solúveis pode variar devido a fatores climáticos, variedade, solo e adição de água durante o processamento, causando a diminuição dos teores de sólidos solúveis.

$\mathrm{O}$ alto teor de umidade encontrado no repolho in natura e nos extratos pode causar uma rápida deterioração, já que a umidade tem grandes ligações com a propagação de microrganismos deterioradores de alimentos. Pesquisa realizada por Santos (2013) indicaram valores próximos ao constatado na pesquisa, com valores variando de $94,64 \%$ e $90,90 \%$ para o extrato e repolho in natura, respectivamente.

O conteúdo em cinzas em uma amostra alimentícia representa o total de minerais podendo, portanto, ser utilizado como medida geral da qualidade, e frequentemente são utilizado como critério na identificação de alimentos. O conteúdo em cinzas torna importante para os alimentos ricos em certos minerais, o que implica em seu valor nutricional (ZAMBIAZI, 2010). Nesta pesquisa obtiveram quantidades de cinzas próximas ao apresentado na Tabela Brasileira de Composição de Alimentos (TACO), a qual analisou amostras de Repolho Roxo cru (TACO, 2011).

O repolho in natura estudado, obteve teores proteicos de 1,6 semelhantes aos valores exposto na Tabela de Composição de Alimentos - (TACO, 2011)

Verificou-se que teores de vitamina $\mathrm{C}$ na hortaliça para o repolho roxo in natura, foi de $46,32(\mathrm{mg} / 100 \mathrm{~g})$, o extrato obtiveram valores variando de 41,69 a 44,48 mg/100g para o extrato alcoólico e aquoso, respectivamente (Figura 11). Pesquisa realizadas por Ohse (2001), constatou valores de vitamina C variando de 41,89 a 19,24 (mg/100g) em alface produzido em Santa Maria/RS. Comparando-se estes teores com os relatados por Ferreira et. al. (2002) em hortaliças convencionais, como couve $(60 \mathrm{mg} / 100 \mathrm{~g})$, brócolis (111 $\mathrm{mg} / 100 \mathrm{~g})$ e couve-flor $(72 \mathrm{mg} / 100 \mathrm{~g})$, constata-se que a espécie pesquisada neste estudo apresentam como fonte de vitamina $\mathrm{C}$.

Para a quantificação de antocianina, o repolho in natura obteve-se uma média de $6,58 \mathrm{mg} / 100 \mathrm{~g}$, enquanto que os extrato obtiveram valores variando de 4,58 a 5,33 mg/100g (extração alcoólica e extração aquosa, respectivamente). Valores inferiores estudados por Machado (2013), onde encontrou teores de 7,89 (mg/100g da amostra). Pesquisa realizada por Gioppo (2011), encontrou valores muito abaixo encontrado nesse estudo, com valores de $0,12 \mathrm{mg} / 100 \mathrm{~g}$ para repolho roxo minimamente processado.

As hortaliças podem sofrer mudanças de temperatura durante o processamento, estocagem e preparo doméstico. Segundo Mazza e Miniati (1993), o aumento da temperatura pode causar destruição logarítmica das antocianinanas. Goffeyet al. (1981), todavia, afirmam que isso nem sempre acontece, pois para algumas antocianinas o aumento na temperatura pode favorecer a produção de complexos ou reações de polimerização durante a degradação, que estabilizam os pigmentos. Processos utilizando baixo tempo em alta temperatura têm sido recomendados para melhor retenção dos pigmentos. 
Tabela 1 - Caracterização físico-química de Repolho Roxo e dos seus extratos concentrado.

\begin{tabular}{lccc}
\hline & Repolho in natura & Extração alcoólica & Extração aquosa \\
\hline pH & 5,9 & 5,81 & 5,83 \\
Solidos Soluveis $\left({ }^{\circ} \mathbf{B}\right)$ & 3,2 & 2,5 & 2,6 \\
Umidade (\%) & 90,03 & 95,5 & 97,8 \\
Cinzas (\%) & 0,88 & 0,77 & 0,55 \\
Proteína (\%) & 1,6 & 0,36 & 0,4 \\
Vitamina c (mg/100g) & 46,32 & 41,69 & 44,48 \\
Antocianina (mg/100g) & 6,58 & 4,58 & 5,33 \\
\hline
\end{tabular}

Para o resultado de melhor rendimento aplicado nas extrações, foi observado na extração aquosa representado na Figura 1, aonde obteve-se uma quantidade de $50 \%$ do volume inicial, para o extrato alcoólico a quantidade foi de $30 \%$ do seu volume inicial representado na Figura 2.

Figura 1 - Rendimento do extrato pelo método aquoso

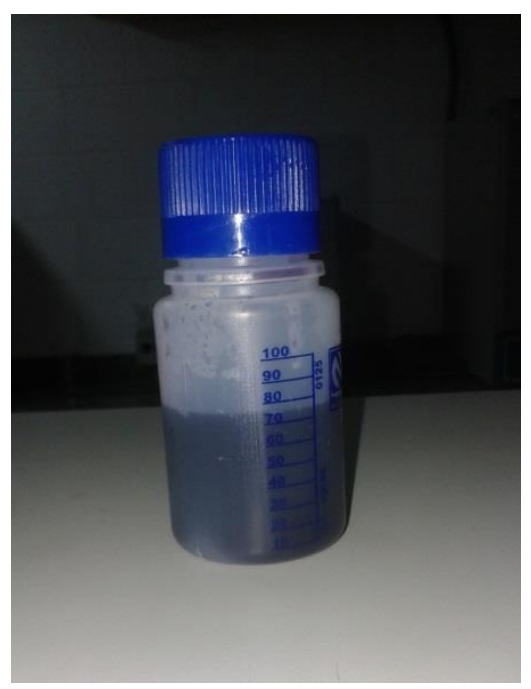

Fonte: Autores

Figura 2 - Rendimento do extrato pelo método Alcoólico

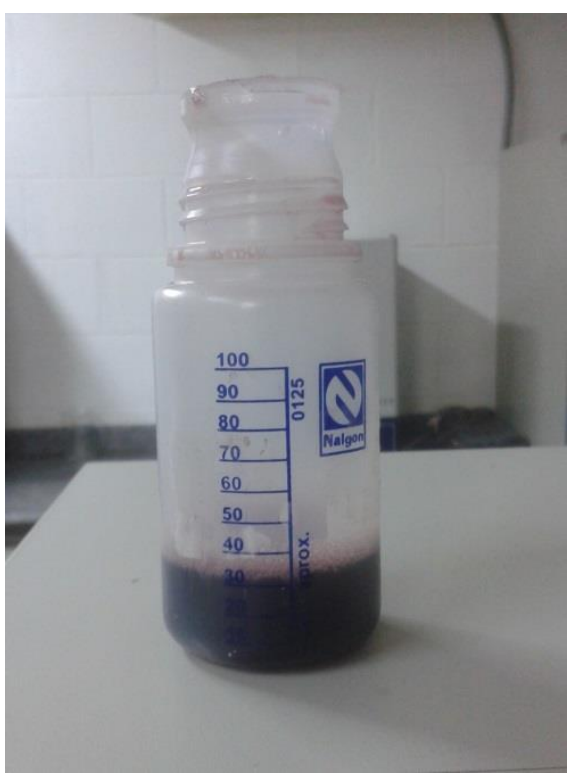

Fonte: Autores

\section{CONCLUSÕES}

Valores obtidos de 5,90 para análises de $\mathrm{pH}$, afirma-se que o repolho roxo é um alimento não ácido e favorável à presença e desenvolvimento de microrganismos patogênicos.

Para o teor de proteína foi observado à perda significativa da mesma, onde o repolho in natura apresentou valores de $1,6 \mathrm{mg} / 100 \mathrm{~g}$ os extratos obtidos com valores máximos de 0,40 mg/100g.Observou-se que o repolho roxo é fonte de vitamina $\mathrm{C}$, e não teve grandes perdas de vitamina no processo de extração do pigmento.

Para o método de extração aquoso, esse teve um rendimento melhor que o alcoólico, observando os custos para obtenção dos produtos, no método alcoólico obteve-se valores mais elevado, por utilizar reagentes e quantidade de energia em longos períodos de tempo, no aquoso foi usado apenas água e um curto período de tempo de energia.

\section{REFERÊNCIAS BIBLIOGRÁFICAS}

CAMPOS, R. S. Processamento mínimo de repolho. Manual de Processamento de Frutas e Hortaliças. Cap 25. pág. 465-482. Embrapa. Brasília, DF. 2007.

COSTA, A. E. Adsorção e Purificação de Corantes Naturais Com Sílica Amorfa. Dissertação (Mestre em Engenharia Química), Departamento de Engenharia Química, Universidade Federal de Santa Catarina, Florianópolis, 91p. 2005.

FERREIRA, W. R.; RANAL, M. A.; FILGUEIRA, F. A. R. Fertilizantes e espaçamento entre plantas na produtividade da couve-da-malásia. Horticultura Brasileira, 20(4): 635-640. 2002.

FILGUEIRA, F. A. R. Novo Manual de Olericultura: agrotecnologia moderna na produção e comercialização de hortaliças.402 p . Viçosa: UFV, 2000 .

FILGUEIRA, F. A. R. Novo manual de olericultura: agrotecnologia moderna na produção e comercialização de hortaliças. p. 279-299. Viçosa: UFV, 2008.

GIOPPO, M. Pós-Colheita de brócolis, repolho roxo e alface sobre diferentes ambientes e reguladores. Dissertação apresentado ao curso de pós-graduação 
emagronomia. Universidade Estadual de Ponta Grossa. p. 29. Ponta Grossa. 2011.

GOFFEY, D. G.; CLYDESDALE, F. M.; FRANCIS, F. J.; DAMON JR., R. A. Stability and complexation of cyaniding-3-glucoside and raspberry juice extract in the presence of selected cations. Journal of Food Protection, v.44, n.7, p.516- 523, 1981.

GOMES, P. M. A., FIGUEIRÊDO, R. M. F., QUEIROZ, A.J. de $M$. Caracterização e isotermas de adsorção de umidade da polpa de acerola em pó. Revista Brasileira de Produtos Agroindustriais, Campina Grande, v.4, n.2, p.157-165, 2002.

INSTITUTO ADOLFO LUTZ (IAL). Métodos FísicoQuímicos para Análise de Alimentos do Instituto Adolfo Lutz. 4 ed. São Paulo, 2008.

WANG, C. J.; WANG, J. M.; WEA, L. L.; CHIA, Y. C.; CHOU, F. P.; TSENG, T. H. Protective effect of Hibiscus anthocyanins against tertbutylhidroperoxideinduced hepatic toxicity in rats. Food and Chemical Toxicology, 38,411-416, 2000.

LÉDO, F. J. S.; SOUZA, J. A.; SILVA, M. R. Avaliação de cultivares e híbridos de repolho no Estado do Acre. Horticultura Brasileira, Brasília, v.18, n.2, p.138-140, 2000.

LÓPEZ O. P.; JIMÉNEZ A. R.; VARGAS F. D. Natural pigments: carotenoids, anthocyanins, andbetalains characteristics, biosynthesis, processing, andstability,Crit. Rev. FoodSci. Nutr,v.40, n.3, p.173$289,2000$.

MACHADO, W. M.;PEREIRA, A. D.; MARCON, M. V. Efeito do processamento e armazenamento em compostos fenólicos presentes em frutas e hortaliças. Exatas Terras. v. 19., p. 17-30, Ponta Grossa, 2013.

MALACRIDA, C. R.; MOTTA, S. Compostos fenólicos totais e antocianinas em sucos de uva.Ciência $e$ Tecnologia de Alimentos, 2005. vol. 25, 659-664.

MAZZA, G.; BROUILLARD, R.Recent developments in the stabilization of anthocyanins in food products.FoodChemistry, Oxford, v.25, p.207-225, 1987.

MAZZA, G.; MINIATI, E., Anthocyanins in Fruits, Vegetables, and Grains. CRC Press, London, p. 362. 1993.

OHSE, S.; NETO, D. D.; MARODIN, V. S.; MANFRON, P. A.; AITA, A. TEORES DE NITRATO E DE VITAMINA C EM ALFACE PRODUZIDA EM
SANTA MARIA/RS: UM ESTUDO PRELIMINAR. INSULA, Florianópolis, $N^{\circ}$ 30, p.63-73. 2001

RAMOS, L.A.; LUPETTI, K. O.; CAVALHEIRO, E. T. G.; FATIBELLO-FILHO, O. j. Eclet. Quim., 2000.

SANTOS, F. A.; SALLES, J. R. J.; CHAGAS FILHO, E.; RABELO, R. N. Análise qualitativa das polpas congeladasde frutas produzidas pela SUFRUTS, MA. Revista Higiene Alimentar, São Paulo, v. 18, n. 119, p.14-22, 2004.

SANTOS, G. R.; DIAS, S. S.; CONSTANT, P. B. L.; SANTOS, J. A. B. CARACTERIZAÇÃO FÍSICOQUÍMICA DO REPOLHO ROXO (Brassica oleracea). Anais do Simpósio Internacional de Inovação Tecnológica-SIMTEC, v. 1, n. 1, 2013.

SILVA, E. O.; CARNELOSSI, M. A. G.; PUSCHMANN, R.; SOARES, N. F. F.; VANETTI, M. C. D.; MININ, V. P. R.; CAMPOS, R. S. Processamento mínimo de repolho. Manual de Processamento de Frutas e Hortaliças. Cap 25. pág. 465-482. Embrapa. Brasília, DF. 2007.

SOARES, M. H. F. B.; ANTUNES, P. A..; CAVALHEIRO E. T. G., Revista Química Nova, 2001.

TIVELLI, S. W.; PURQUERIO, L. F. V. Repolho. 2005. Disponível em: <http://www.iac.sp.gov.br/Tecnologias/Repolho/Repolh o.htm>. Acesso em: 20 nov. 2013.

TACO. Tabela de Composição de alimentos. Campinas: NEPA-Unicamp. 161 p. 2011.

TAFFARELLO, D. Extratos de Arrabidaea chica (Humb. \&Bonpl.) Verlot Obtidos Por Processos Biotecnológicos: Otimização da Extração a Avaliação Farmacológica. Dissertação (Mestre em Biotecnologia), Instituto Butantan/IPT, Universidade de São Paulo, São Paulo, 43p. 2008

VOLP, A. C. P.; RENHE, I. R. T.; STRINGUETA, P. C. Pigmentos Naturais Bioativos. Alim. Nutr., v. 20, n. 1, p. $157-166,2009$.

XAVIER, M. F. Estudo da extração de antocianinas em colunas recheadas.. Dissertação (mestrado em Engenharia Química), Universidade Federal de Santa Catarina, Florianópolis, 135f. 2004.

ZAMBIAZI, R. C. Análise Físico Química de Alimentos. Pelotas: Editora Universitária/UFPEL, 202p. 2010. SAS Institute. System for Information, versão 8.0. Cary, 2007. 1 CD Rw. 